Acta Geod. Geoph. Hung., Vol. 38(3), pp. 281-303 (2003)

\title{
DEDUCTION OF TECTONIC STRUCTURE OF NORTH AND CENTRAL SINAI FROM AEROMAGNETIC AND BOUGUER ANOMALY MAPS
}

\author{
Mohamed El-Said El-Bohoty ${ }^{1}$ \\ [Manuscript received October 29, 2001]
}

\begin{abstract}
The aim of the present work is to deduce the tectonic structure of the area and to show the role of the separation methods in the resolution of the multisource of magnetic and gravity implications. The aeromagnetic total intensity map was transformed to the reduced pole aeromagnetic map (RTP). This step was followed by linear wavelength filtering of the RTP aeromagnetic map, and of the Bouguer anomaly map, in order to isolate shallower residual components using different grid intervals. A comparative analysis was carried out for the different filtered RTP aeromagnetic and gravity maps. Statistical trend analysis was applied for the magnetic and gravity data. The study revealed that the area has been affected by three significant tectonic trends, namely: NE-SW, NW-SE and E-W. The RTP aeromagnetic map and Bouguer anomaly maps provided detailed data for 2D modeling of the source. The magnetic and gravity cross section indicates possible sources of the observed anomalies. Only depth of the anomaly sources (mostly in the basement) were determined from magnetic and gravity data to reveal a tectonic zone and structure which leads to a fluid migration. The result of depth estimation to the basement complex revealed that the depth of the basement ranges between $3.2 \mathrm{~km}$ and $4.3 \mathrm{~km}$.
\end{abstract}

Keywords: aeromagnetic survey; Bouguer-anomaly; Sinai tectonics

\section{Introduction}

The area selected for the present study lies between latitudes $30^{\circ} 00-31^{\circ} 10 \mathrm{~N}$ and longitudes $33^{\circ} 00-35^{\circ} 00 \mathrm{E}$ as shown in Fig. 1. The aim of this paper is to find out the structures of the basement rock of the earths crust in the investigated area using the available geophysical and geologic data. The potential field data include the followings:

1. Magnetic data in the form of total intensity aeromagnetic anomaly map, scale 1:700000. The RTP technique was then used on the total aeromagnetic intensity map using the equation of Baranov (1975), and with help of the Geosoft program (1994). The input parameters are: inclination $40^{\circ} 30$, declination $2.1^{\circ}$, magnetic field intensity $43000 \mathrm{nT}$.

2. Gravity data in the form of Bouguer anomaly map, with a scale 1:700000 and contour interval 0.75 milligal.

The potential field data (both gravity and magnetic) were provided by courtesy of the Institute for Petroleum Research and Geophysics; Israel.

\footnotetext{
${ }^{1}$ National Research Institute of Astronomy and Geophysics (NRIAG), Helwan, Cairo, Egypt
} 


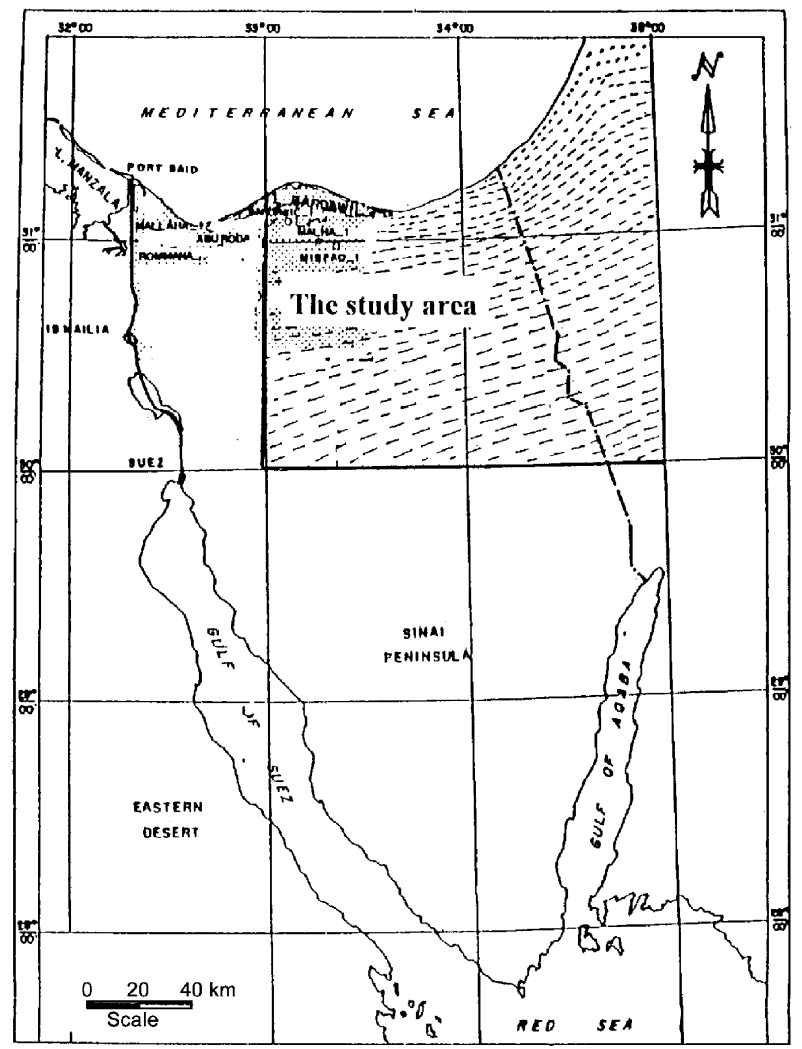

Fig. 1. Location map of the studied area

Qualitative interpretation deals with description of anomalies especially their symmetry, strike, extensions, width, amplitudes, gradients, filtering technique and trend analysis. The quantitative interpretation in this work is based on the following steps, for both gravity and magnetic data:

1. Application of the two-dimensional modeling technique.

2. Parameter calculation of the buried bodies using Hilbert transform technique.

3. Application of suitable methods for depth estimation.

The results achieved by the analysis of these data is that, different possible solutions exist for one problem. This fact, urges us to find a method leading to a single solution. The geological information and borehole data were used to support the interpretation of the gravity and magnetic data as well as find out the relation between the geology, structure, geophysics and the present tectonic activity. 


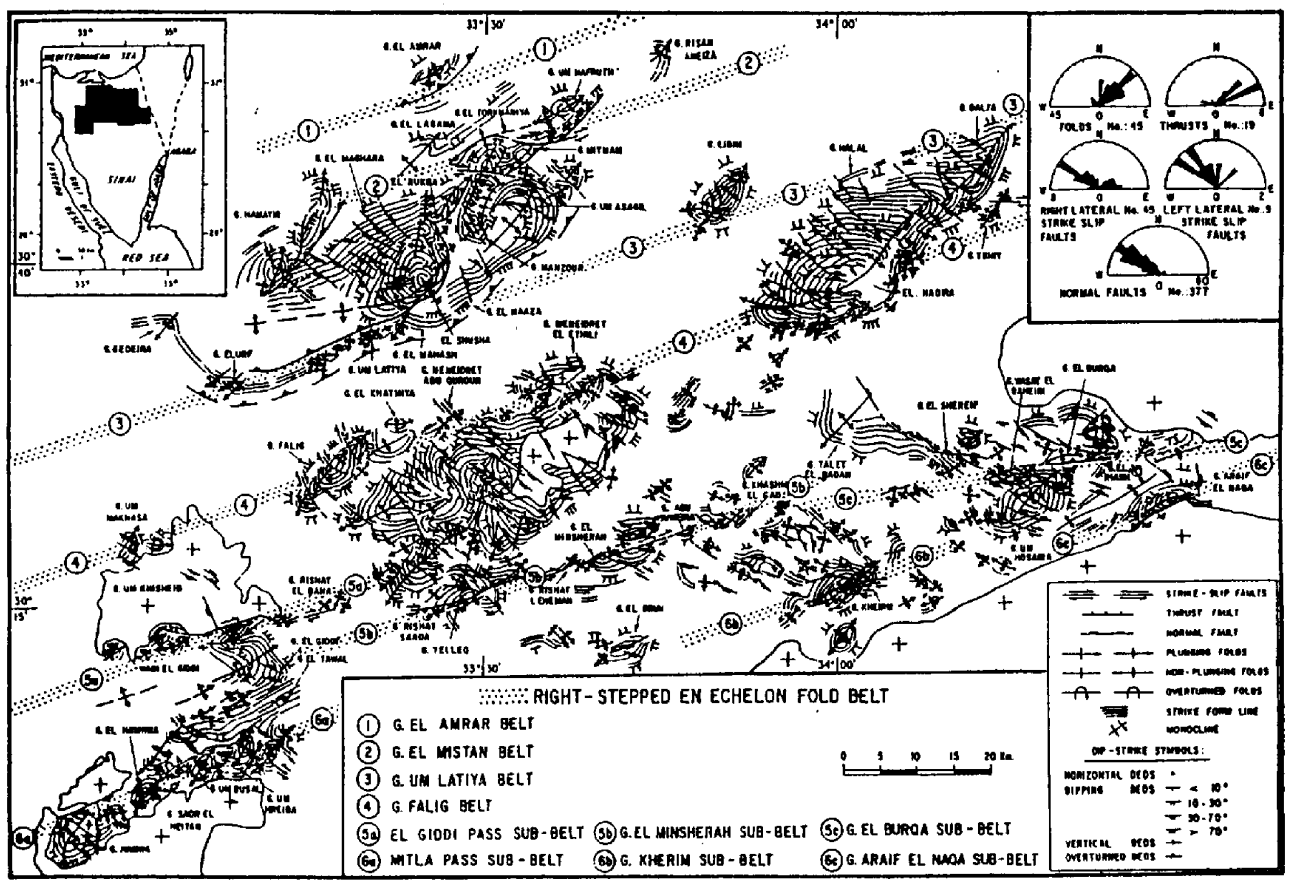

Fig. 2. Structural map of North and Central Sinai

\section{General geological conditions}

The studied area consists of subhorizontal Mesozoic and, Tertiary sediments, creating the plateau of Gebel El Tih and Gebel EL Egma which are drained by the northerly flowing affluence of Wadi El Arish. North of latitude $30^{\circ} \mathrm{N}$, the topography comprises low alluvial plains which are broken by large uplifted domes and anticlines. North of Gebel Maghara and extending nearly to the Mediterranean coast, there is a broad tract of sand dunes, some of which attain heights of $91 \mathrm{~m}$ above sea level. An east-west trending shear zone of a dextral strike slip fault with up to $2.5 \mathrm{~km}$ of displacement has been recognized in North and Central Sinai by Steinitz et al. (1978).

The structural study of North and Central Sinai (Fig. 2) shows the abundance of northeast to east-northeast oriented double plunging anticlines including large (tens of kilometers long, e.g. Gebel Halal), intermediate (several kilometers long, e.g. Gebels El Mnsherah), and small folds, (less than $2 \mathrm{~km}$ in length). The large and intermediate folds are asymmetric (Harland 1971, Lowell 1972, Sylvester and Smith 1976, Said 1990). The northeast deep-seated faults were probably formed by late Triassic rifting in North Africa Arabia that formed the passive continental margin of the Tethys in the East Mediterranean region (Wilcox et al. 1973, Tchalenko 1970, Smith 1971). 


\section{Qualitative interpretation of potential field data}

Descriptive and structural indications of the RTP magnetic anomaly map

A general outlook to the RTP magnetic map (Fig. 4) and of the total intensity aeromagnetic map (Fig. 3) shows that the northward shift of the implied anomalies of the map after removing the effect of the inclination of the magnetic field at the study area. Also, the number of anomalies becomes larger with comparable decrease of their ariel extension and the increase of their vertical relief. The inspection of the RTP aeromagnetic anomaly map of the area (Fig. 4), reveals that the magnetic field shows up in the area with a maximum relief of about $600 \mathrm{nT}$, and minimum of about $160 \mathrm{nT}$. They include several local anomalies in the central and northeastern part of the studied area. These anomalies have different relief's, polarities and shapes. The general magnetic trends of these regions are almost NW-SE, NE-SW and E$\mathrm{W}$. The anomalies along the northeastern part, characterized by irregular shape, low gradient with east-west trending magnetic low reflect a structural low. Further to south, the magnetic anomalies are composed of two closures of different sizes and shapes and characterized by its moderate gradient, positive polarities, with size varying from $350 \mathrm{nT}$ to $550 \mathrm{nT}$. The predominant regional magnetic contour trend is mainly in NW-SE and NE-SW direction. The anomalies are suggested to arise from a structural high. In the central part of the area the anomalies are characterized by elongated contour pattern, steep gradient with north-east trending magnetic high. These steep gradient anomalies indicate that the area is structurally controlled by NE-SW fault zones.

\section{Descriptive and structural indications of the Bouguer anomaly map}

The inspection of the Bouguer anomaly of the investigated area (Fig. 5) reveals that the gravity field in the area has a maximum relief of about +105 mgal in the western part and minimum of about $+30 \mathrm{mgal}$. The regional gravity field in the central part influences the well-defined local gravity anomalies in the southeastern parts of the area due to lithologic variations either within the basement or in the sedimentary section itself or in both. The general trend of this field are NE-SW and NW-SE. Also, most of the steep gradients have alternative negative and positive anomalies at the central part of the map, what indicates that the area is structurally controlled by tectonics having major axis in NW-SE and NE-SW directions. The western part has anomalies with definite polarities and characterized by irregular contouring pattern, with positive value, different sizes and shapes and from moderate to high gradients. The source of the anomaly may be due to an uplifted block of the denser crustily rocks.

\section{Horizontal gradient maps}

These maps were prepared from the RTP aeromagnetic intensity and Bouguer anomaly maps using the Hilbert transform technique of Stanley (1977). The inspection of the horizontal gradient of the RTP magnetic anomaly map (Fig. 6) reveals that the central part of the area being affected by several local anomalies of different relief, polarities and shapes. The general trend is NE-SW and NW-SE. Also 


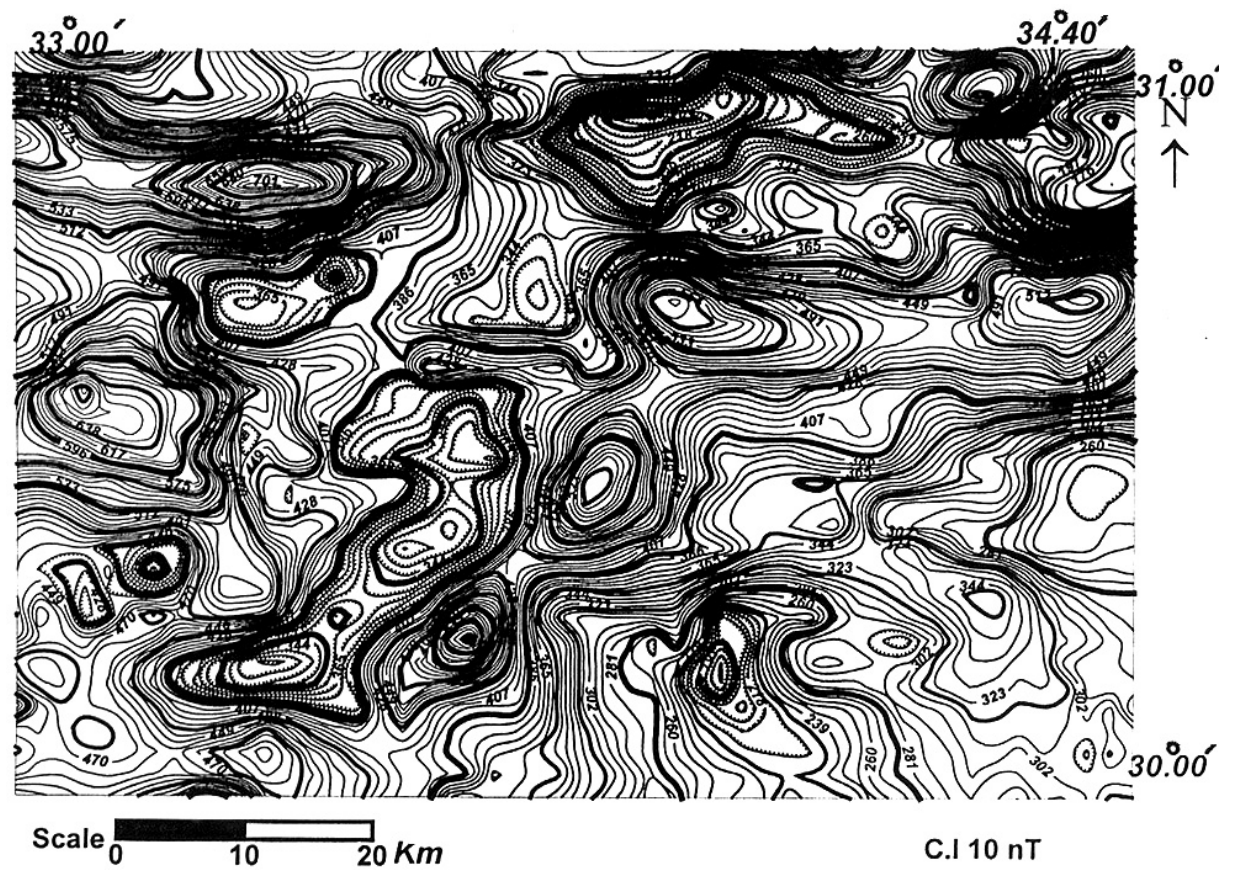

Fig. 3. Total aeromagnetic anomaly map of the studied area. C.I. $=10.00 \mathrm{nT}$

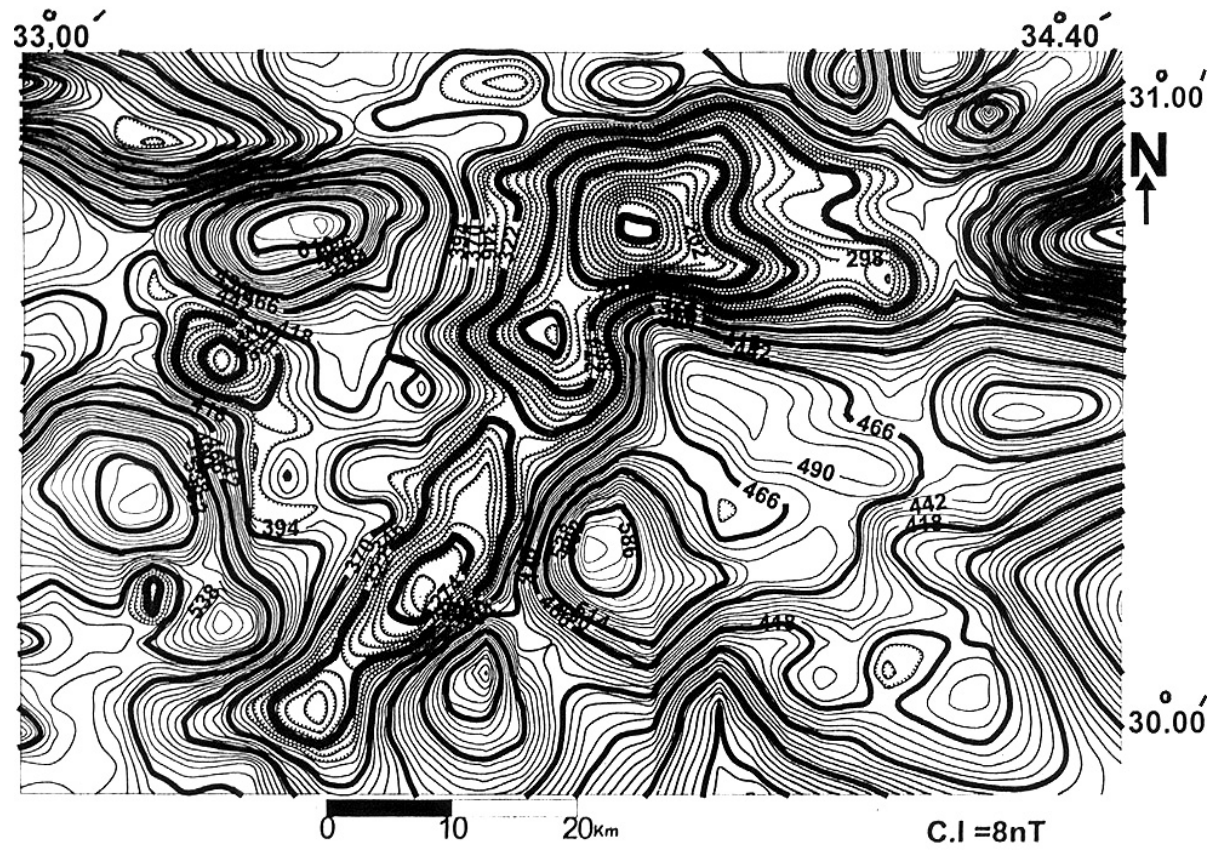

Fig. 4. RTP aeromagnetic anomaly map of the studied area. C.I. $=8.00 \mathrm{nT}$ 
it is interesting to mention here that, most of the steep gradients are structurally controlled with the major tectonic axis trending N 45 E.

The horizontal gradient of the gravity anomaly map (Fig. 7) indicates that the general trends are NE-SW and NW-SE directions, several other minor trends are also present. Most of the steep gradients in the eastern and western parts of the area are structurally controlled with NE-SW and NW-SE tectonic trends which separate this area from the main depression and platform area.

\section{Filtering method}

In the present work, the linear wavelength filtering (Baranov 1975) of the RTP aeromagnetic map was carried out utilizing two types of filtering.

a) Low cut off the residual anomalies with short wavelength, high frequency and small depths.

b) High cut off the regional anomalies with long wavelength, frequency and small depths.

These filtering have been applied on the RTP aeromagnetic map and on the Bouguer anomaly map (Figs 4 and 5). A variation in the relief and polarity of the anomalies has been observed. The major tectonic trends deduced from the residual, and regional magnetic filtered maps (Figs 8 and 9) indicate that the local structures are controlled by the regional deeper structures which have E-W, NE-SW, NW-SE trends. Generally, these trends occupy the high magnetic anomalies. The anomalies along this axis of magnetic high have a large arial extension and high gradient, which indicates shallow depth to the basement.

The gravity filtered maps (residual and regional, Figs 10 and 11), reveal three structural features indicated by linear anomalies having their extension in NE-SW, NW-SE and E-W directions. These anomalies are structurally controlled by fault trends in NE-SW, and NW-SE direction.

\section{Structural trends as inferred from the observed and filtered potential anomalies}

The RTP aeromagnetic map, together with the Bouguer gravity map, and the regional filtered maps, were used to determine the common structural trends in the area. The azimuth, length and trends for each detected lineament on the different maps were measured clockwise from the north. The results are fault systems deduced from the RTP aeromagnetic map, Bouguer gravity map and regional filtered maps (Figs 4 and 5, 9 11), they are plotted in the form of frequency curves (Fig. 12). Three predominant sets of lineaments exist which show different intensities of length distributions. These main sets trend N 55 W, N 55 E, and E-W. The three trends represent the predominant tectonic trends in the investigated area, from the magnetic and gravity point of view. Study of the frequency curves for the length percentage (L\%) of RTP aeromagnetic map, Bouguer gravity map, and regional filtered maps showed, the following trends.

Acta Geod. Geoph. Hung. 38, 2003 


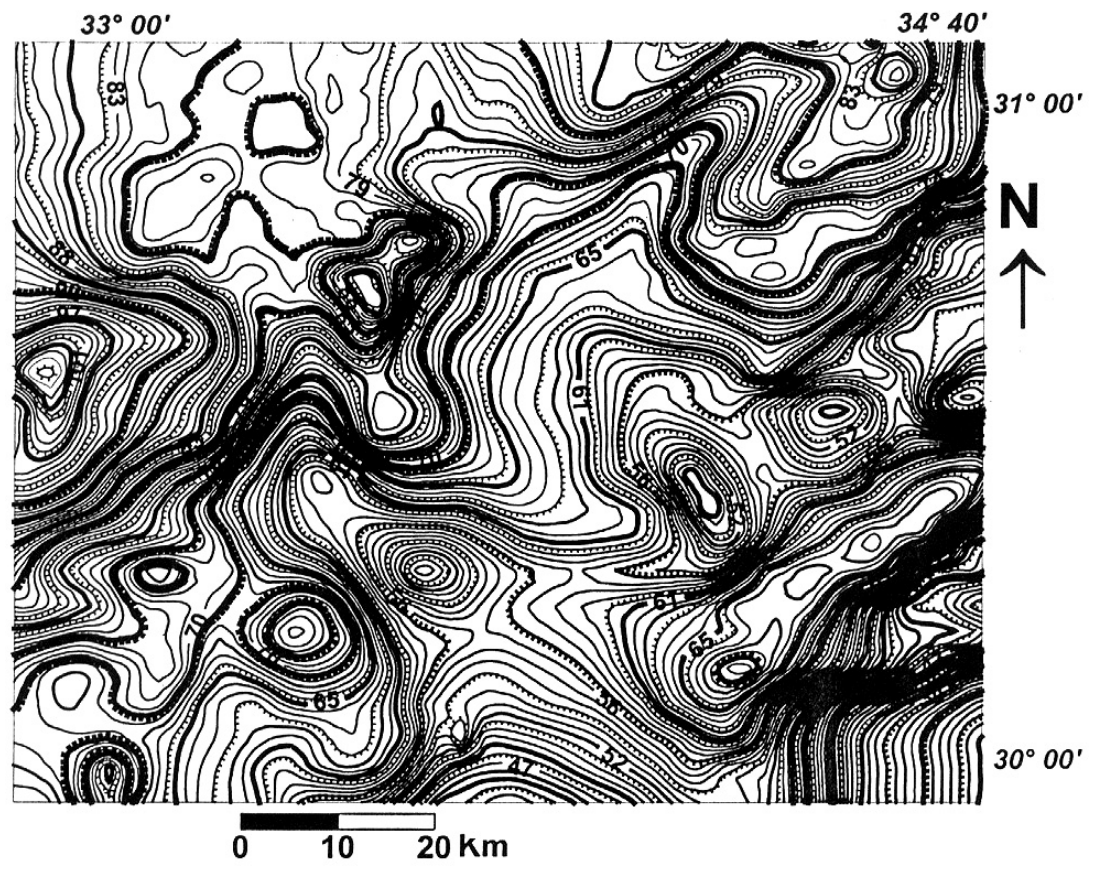

Fig. 5. Bouguer anomaly map of the studied area. C.I. $=0.75 \mathrm{mGal}$

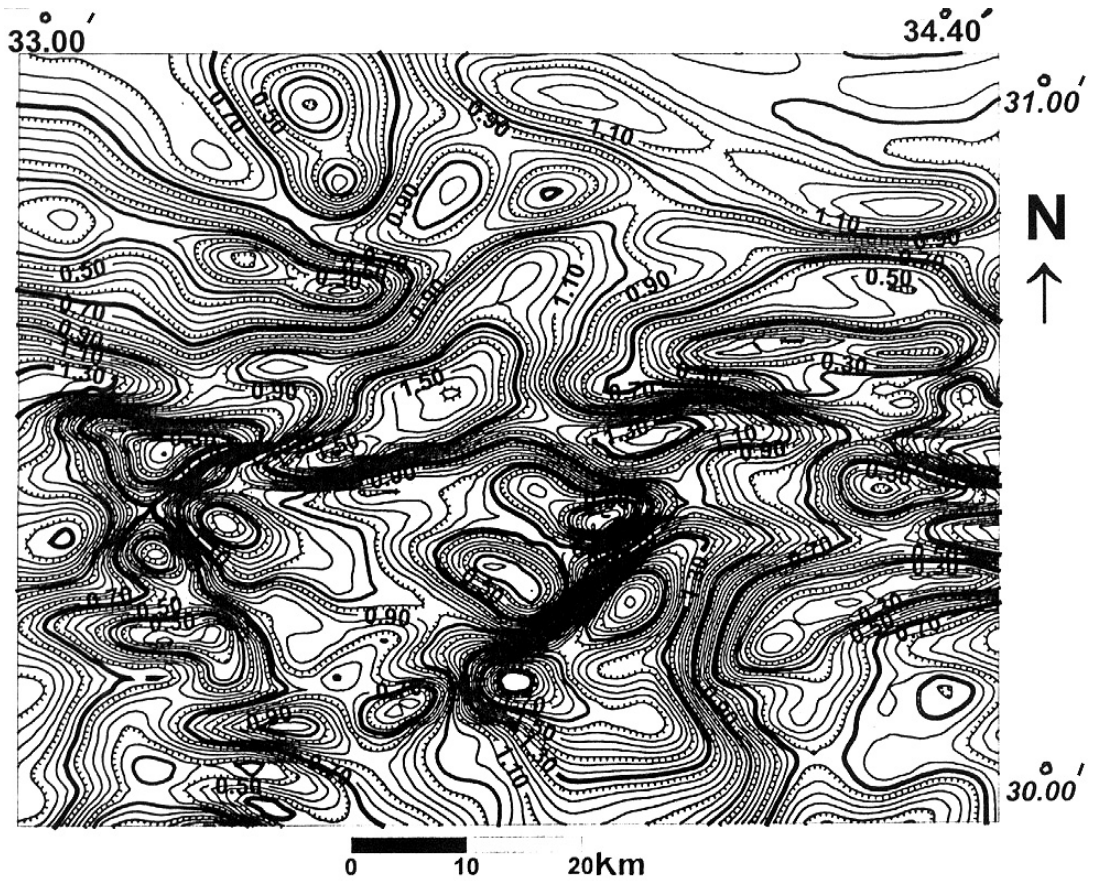

Fig. 6. Horizontal gradient of magnetic anomaly map. C.I. $=0.04 \mathrm{nT}$ 


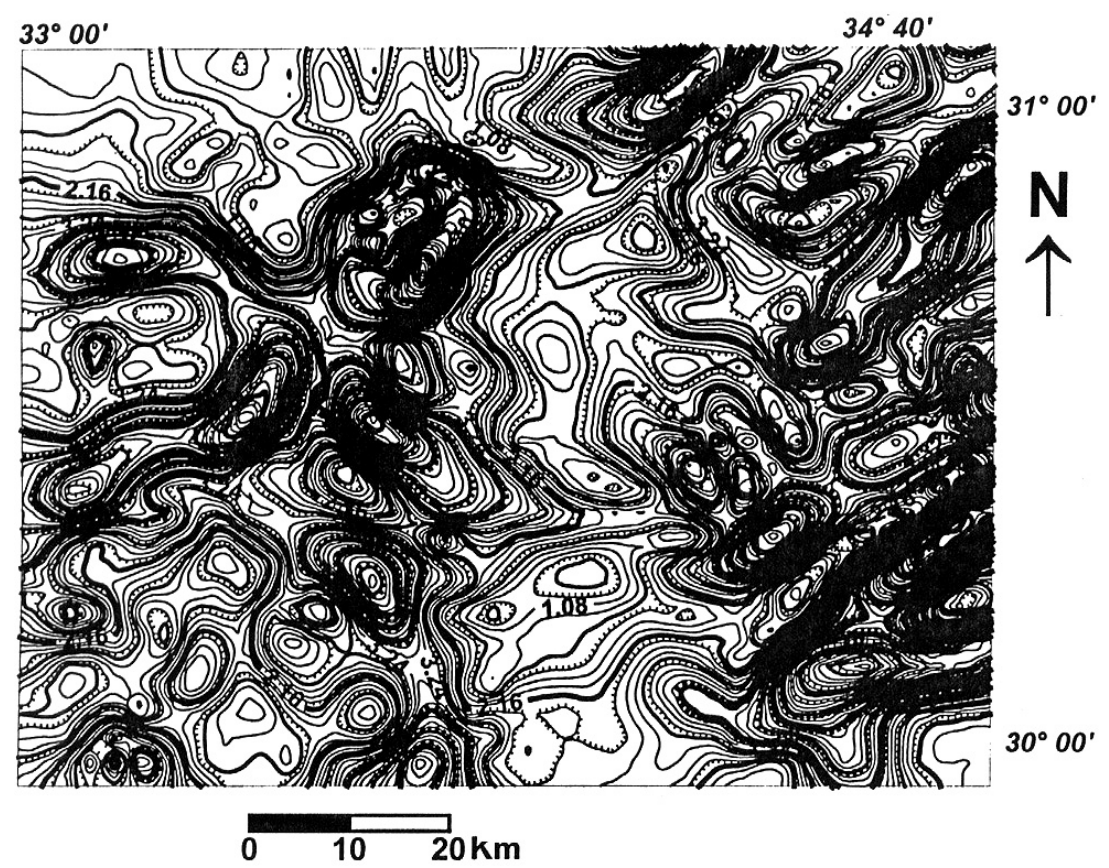

Fig. 7. Horizontal gradient of gravity anomaly map. C.I. $=0.18 \mathrm{mGal}$

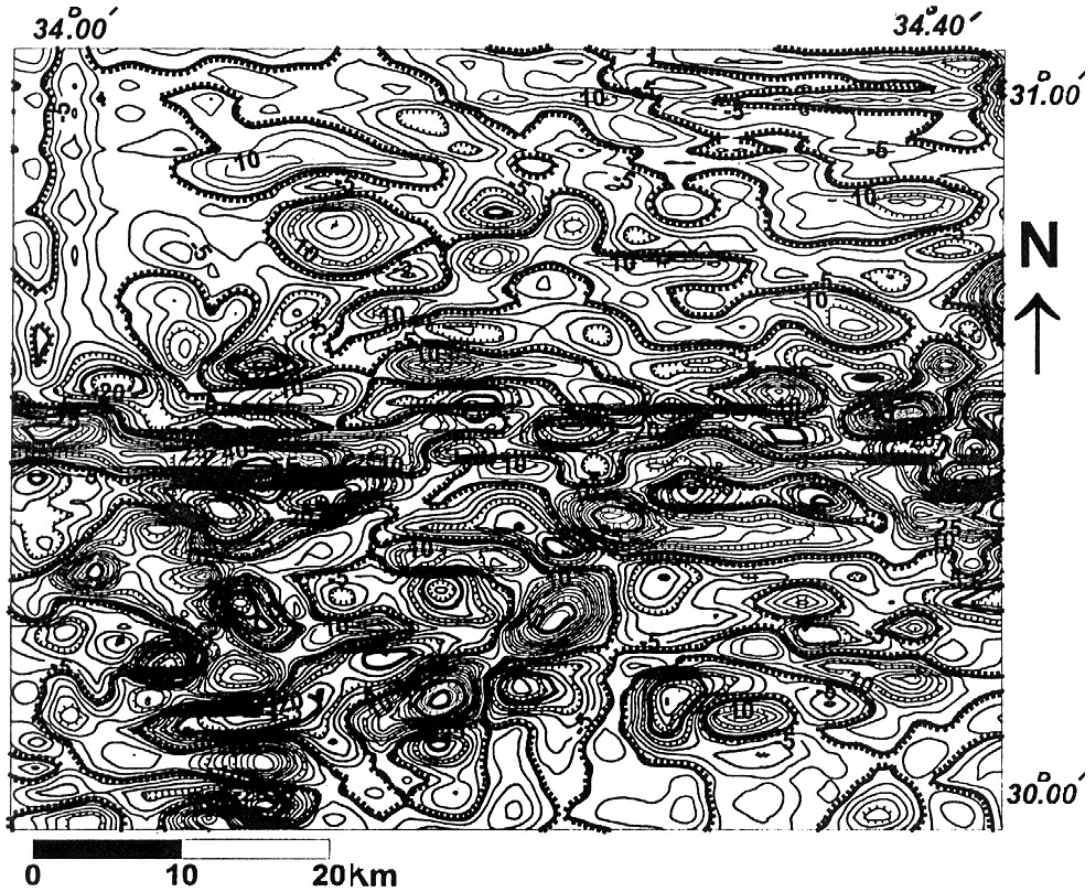

Fig. 8. Residual magnetic filtered map. C.I. $=3.00 \mathrm{nT}$ 


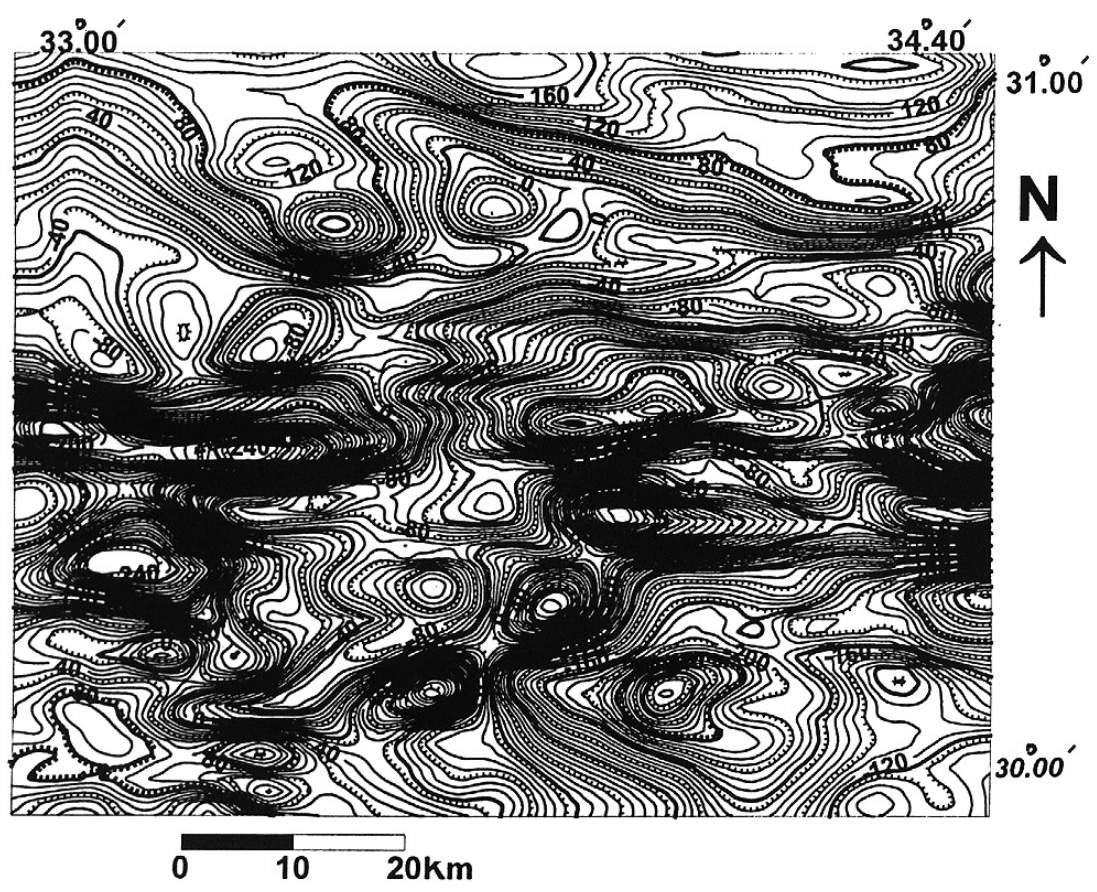

Fig. 9. Regional magnetic filtered map. C.I. $=8.00 \mathrm{nT}$

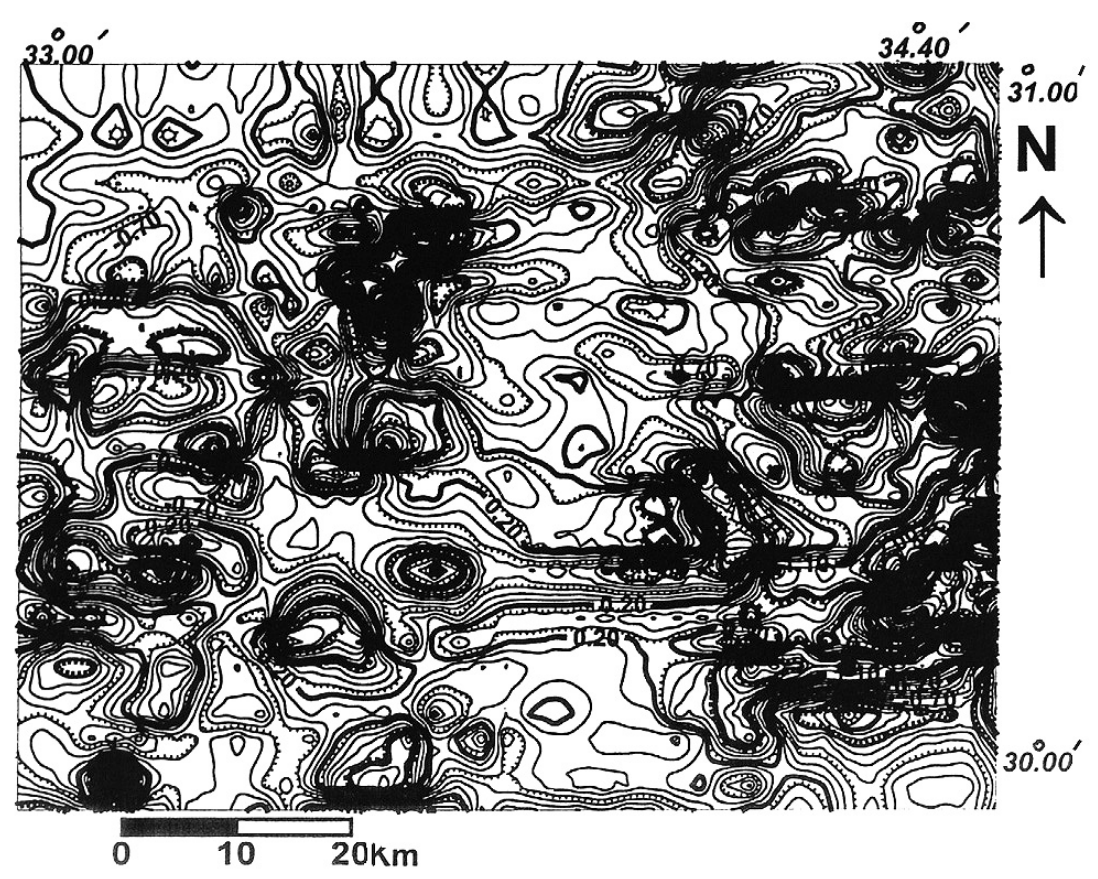

Fig. 10. Residual gravity filtered map. C.I. $=0.18 \mathrm{mGal}$ 


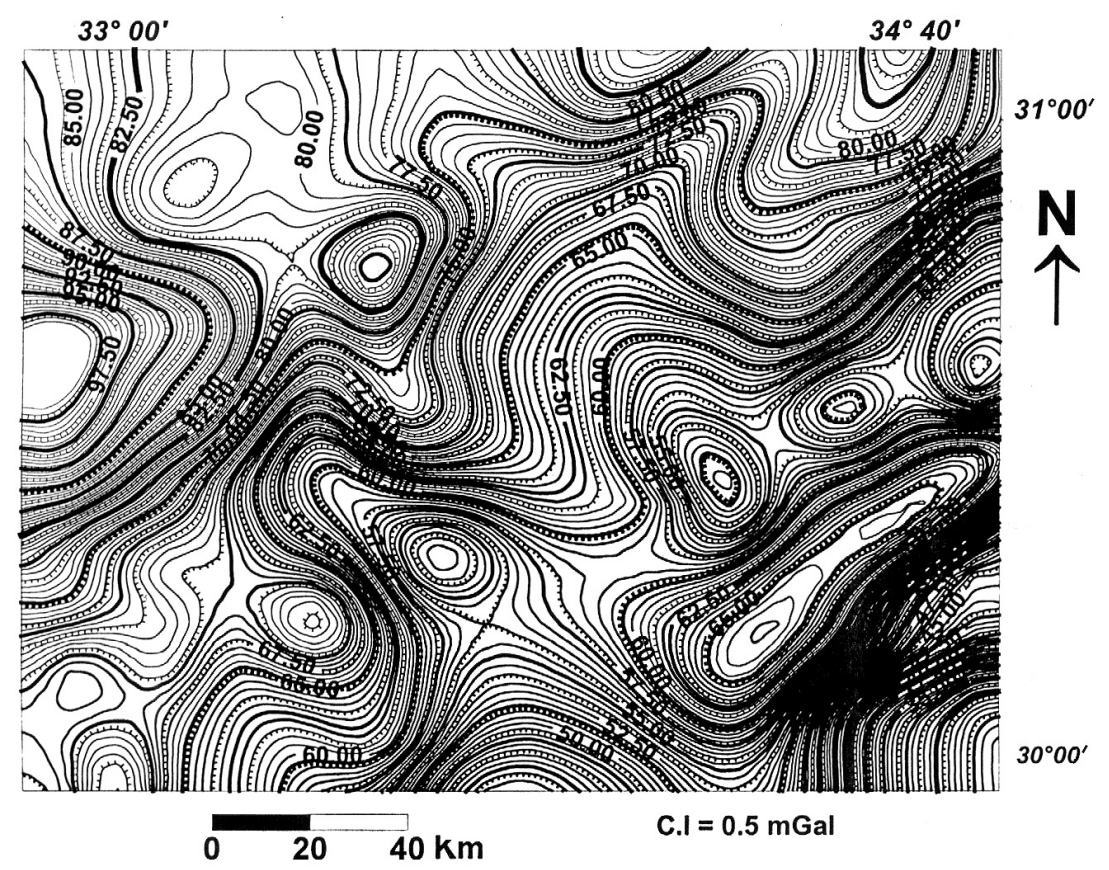

Fig. 11. Regional gravity filtered map

The N 55 E trend (Quatra trend)

This is the predominant trend within the investigated area. The statistical analysis of the trends deduced from the RTP aeromagnetic map, Bouguer gravity map, and regional filtered maps. Figure 12 revealed that the N 55 E trend represents one of the most prevailing faulting direction in the studied area. This controversy can be attributed to the fact that the distinctness with which faults appear on the magnetic and gravity maps depends principally on the existence and the strength of magnetic and gravity contrast in the body rocks involved (Domazalaski 1966).

\section{The $N 55$ W trend}

This trend is second in abundance to the N $55 \mathrm{E}$ trend according to its characteristics, and has a strong relation to trends deduced from the RTP aeromagnetic map, Bouguer gravity map and regional filtered maps (Fig. 12). It is the principal controlling direction for the east African and west European rift systems (Halsey and Gardner 1975).

\section{The $N 85 W(E-W$ trend)}

This trend in the area of investigation is $\mathrm{E}-\mathrm{W}$ trend (Mediterranean direction) and takes a mean strike of $\mathrm{N} 85 \mathrm{~W}$ and includes all the faults striking from $\mathrm{N} 80 \mathrm{~W}$ to E-W. This direction is referred to as Tethyan trend (Said 1962). It occurs as a fault direction in North and Central Sinai. This trend can be detected on both the 

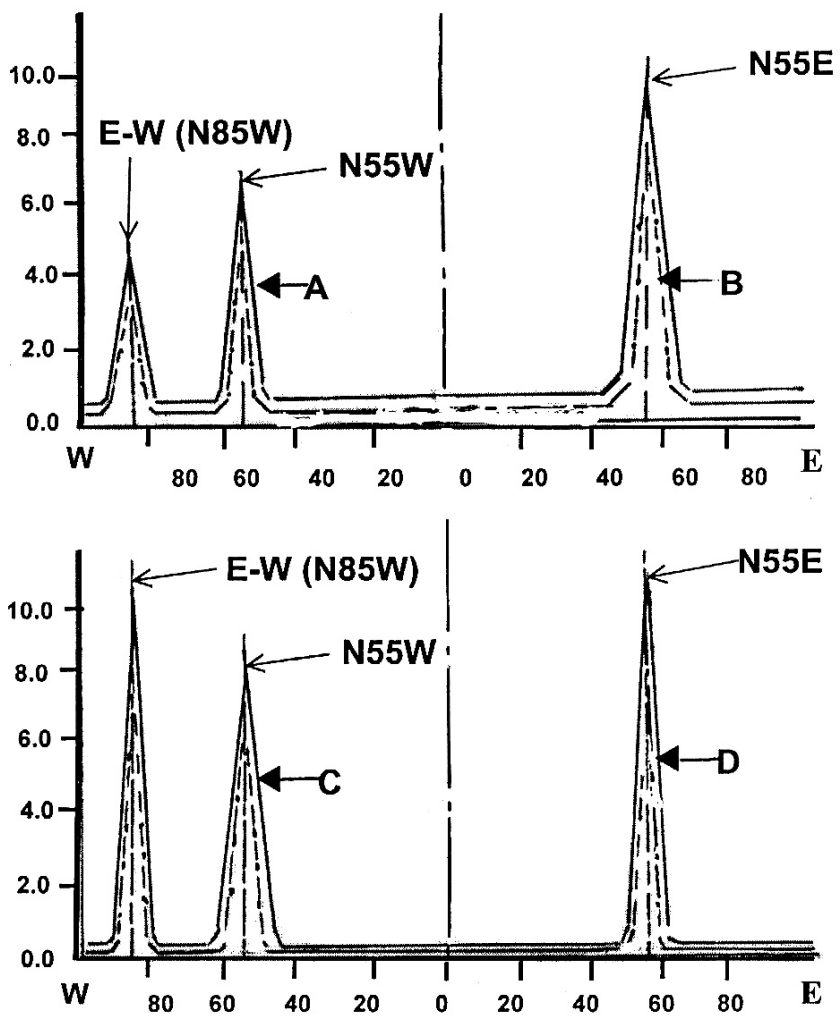

Fig. 12. Frequency distribution from statistical analysis of magnetic trends deduced from (A) RTP aeromagnetic anomaly map; (B) regional magnetic filtered map; (C) Bouguer anomaly map and (D) regional gravity filtered map

gravity and magnetic frequency curves. However it is less characteristic than the previously mentioned ones.

\section{Quantitative interpretation of the potential field data}

The quantitative interpretation of gravity and magnetic anomalies has numerous limitations and assumptions, which make it a non-straightforward procedure. Thus the author applied several methods and techniques to test their validity, and the most suitable method (or methods) was selected and applied. Methods of quantitative analysis in this work based on the following steps for both gravity and magnetic data:

A) Application of the two-dimensional modeling technique on selected profiles of the RTP aeromagnetic and Bouguer anomaly maps to determine the basement configuration.

B) Calculation of the parameters of buried bodies using Hilbert transform technique. 


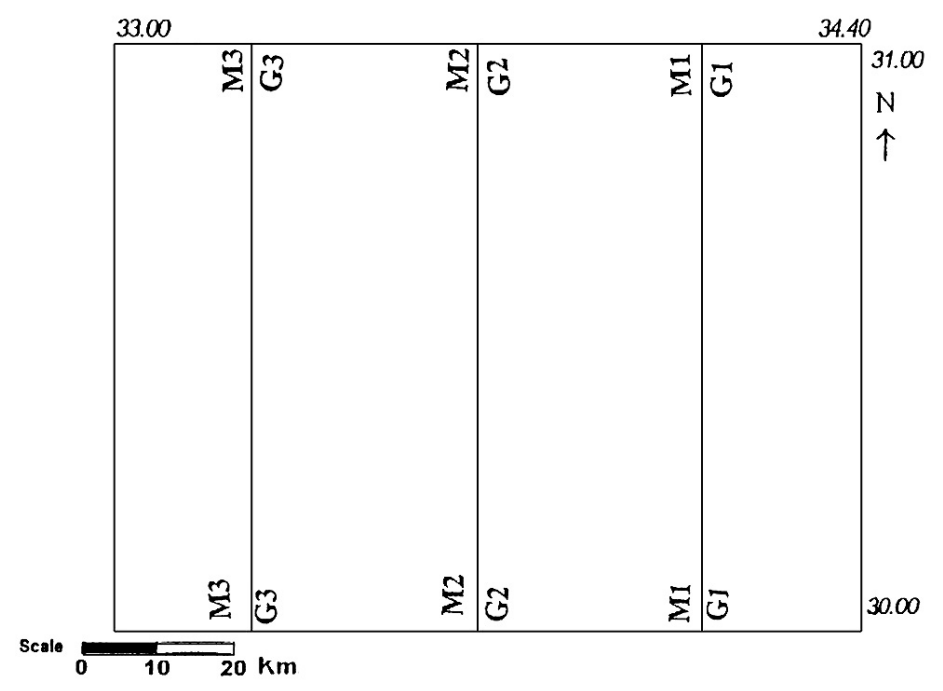

Fig. 13. Location map of the selected magnetic and gravity profiles used in two-dimensional anomaly modeling

C) Application of a suitable method to calculate the depth of the top of the basement surface and basement intrusions.

\section{A) Two-dimensional magnetic and gravity modeling}

The two-dimensional modeling usually involves the fitting of geophysical parameters to potential data. Strictly speaking, potential modeling could be an inverse solution to potential problems, which cannot be unambiguous. This modeling is principally based on the calculation of the magnetic and gravity effect of two-dimensional bodies having arbitrary cross-section, along selected profiles (Fig. 13). In the present study, the author used GM-SYS program, produced by Northwest Geophysical Associates, Inc. USA (1995), to calculate the expected subsurface structural condition along the three different profiles running perpendicular by the general structure and covering the investigated area. The selected profiles are taken from RTP aeromagnetic maps (M1, M2, and M3) and from Bouguer gravity map (G1, G2, and G3). The magnetic and gravity profiles having the same length are taken from the same sites (Fig. 13). The magnetic susceptibility of the upper igneous cutting is 0.1235 S.I. units while the lower igneous cutting has 0.0768 S.I. The magnetic field responses computed for the geological models used a magnetic declination of $2^{\circ}$ east and magnetic field inclination $42^{\circ}$. The used regional magnetic field intensity used was $42000 \mathrm{nT}$, which is the appropriate interpolated value of 2000, IGRF for the time of acquisition. As related to the gravity field, the average density contrast varies between 0.2 and $0.32 \mathrm{~g} / \mathrm{cm}^{3}$.

Investigating the 2D model along the magnetic and gravity profiles (M1-M1 and G1-G1, Fig. 14), one can see that the model exhibits four peaks. The magnetic 
peaks indicate the locations of shallow magnetic structures underlying of highest magnetization. The depth to the top of the basement rocks across those peak ranges $2.1 \mathrm{~km}-2.4 \mathrm{~km}$, and of the deeper parts is $2.7 \mathrm{~km}-3.1 \mathrm{~km}$, from 1999.GRF value. It is obviously clear that the depth to the basement is increasing from the north to the south along the profile. Also the model contains a wide depression in the central part of the profile. The depth to the basement surface across this depression is about $4.2 \mathrm{~km}$. It is evident from the modified model along magnetic and gravity profiles (M2-M2, and G2-G2, Fig. 14) that the model contains a wide depression in the central part, and has the following parameters: depth to the top of depression is $2.2 \mathrm{~km}$ and the depth to the bottom is $2.7 \mathrm{~km}$. Width of the depression is $4.8 \mathrm{~km}$. Study of the modified model along profiles M3-M3 and G3-G3 (Fig. 14). shows that the model exhibits two peaks. The depths of the basement surface at those peaks are $2.0 \mathrm{~km}$ and $2.4 \mathrm{~km}$. Also the model contains two depressions in the central part of the profile. The depths of the basement surface at those depressions are 3.1 and $3.6 \mathrm{~km}$.

\section{B) Calculation of the parameters of buried bodies using Hilbert transform technique}

The Hilbert transform technique provides interpretation with a simple and efficient method that can be used for calculation of the parameters of buried bodies. To evaluate the parameters of buried bodies, some magnetic and gravity profiles have been used, as indicated in the location maps (Figs 15 and 16). Figures 17 and 18 demonstrate examples on the quantitative interpretation of the magnetic and gravity anomalies along profiles A2-A2 and G3-G3. The results of calculation of dyke parameters are listed in Table I.

\section{Depth estimation}

There are several methods for the quantitative interpretation that have been introduced for delineating the bedrock by estimating the widths and depths of the anomalous bodies. In this study, depth estimation methods have been applied to a set of profiles of different structural units. The raw data upon which the processed examples are based on are the RTP aeromagnetic anomaly map and Bouguer gravity map (Figs 4 and 5).

Poorna method (1985)

The advantage of this method is the non-dependence upon the position of zero level, which is critical factor for other methods. It has been applied with great accuracy to five anomaly profiles with defined flanks at maximum and minimum inflection points.

The magnetic profile (P5P5, Fig. 19). has several characteristics which can be effectively used in estimation of the source characteristics $\mathrm{X} 0$ (or the location $\mathrm{X}=0$ on the distance axis). This profile has characteristics maxima (M: XM) and minima

$(\mathrm{m}: \mathrm{Xm})$ points, the co-ordinates of these maxima and minima are determined 

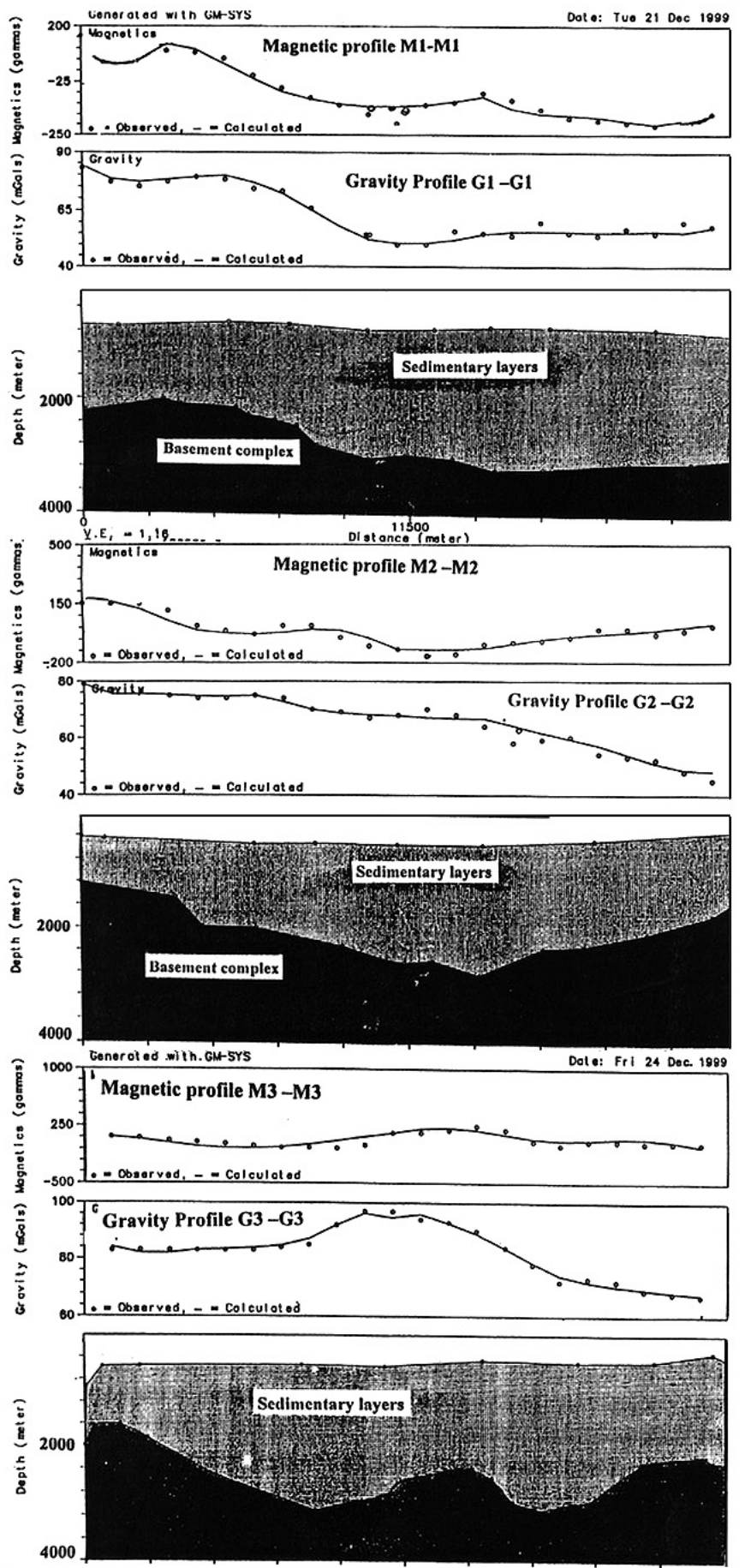

Fig. 14. Two-dimension models along profiles (G1-G1, G2-G2, G3-G3 and M1-M1, M2-M2, M3-M3) 


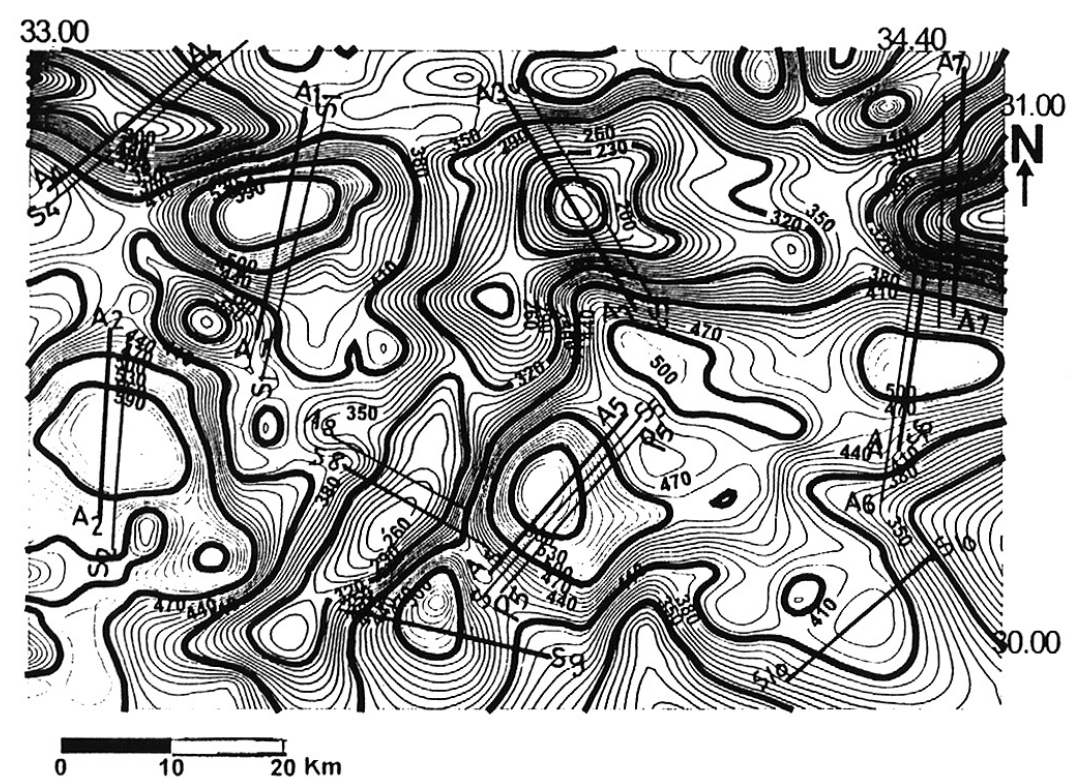

Fig. 15. Location map of the magnetic selected profiles for depth. Computation using different methods and techniques, where A-A: profiles used in Hilbert transform technique, S-S: profiles used in spectral analysis technique, P-P: profiles using in Poorna method (1985)

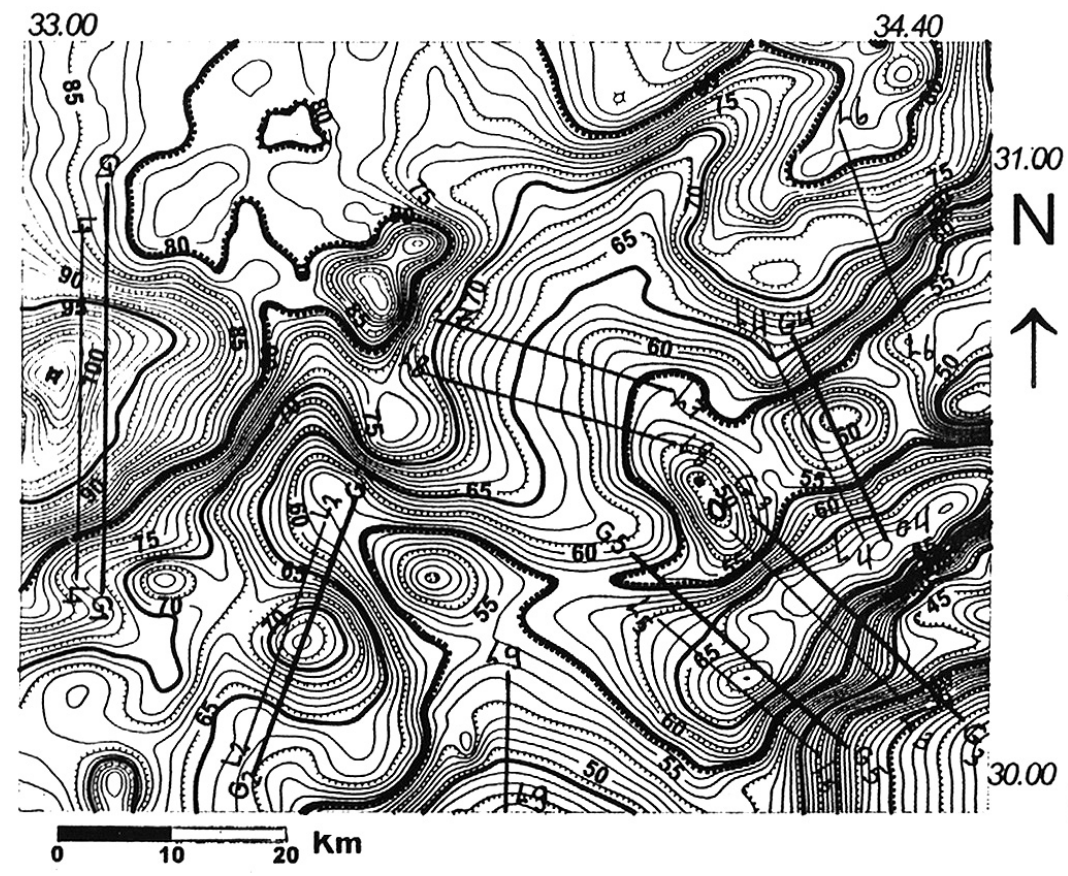

Fig. 16. Location map of the gravity selected profiles for depth. Computation using different methods and techniques, where G-G: profiles used in Hilbert transform technique, L-L: profiles used in spectral analysis technique 


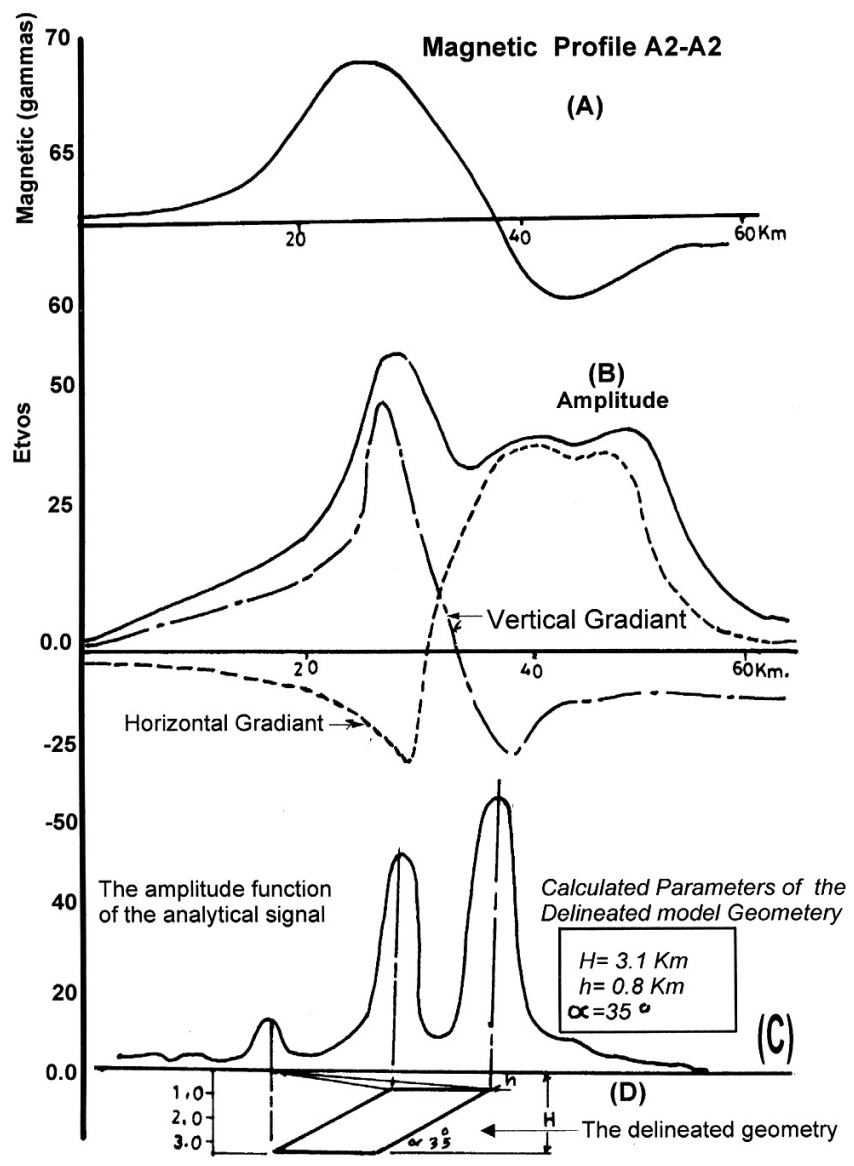

Fig. 17. Quantitative interpretation along magnetic profile A2-A2

by deriving the analytical expression for the horizontal gradient of the observed magnetic profile.

The entire interpretation process in this gradient-based method for interpreting the thick dyke magnetic anomaly is summarized in four steps as follows:

1. Locate the epicentral position $\mathrm{X}=\mathrm{x} 0$ of the observed magnetic profile and determine the values of XM and Xm relative to it using the method of Powell (1967).

2. compute the horizontal gradient (FX) profile from the observed magnetic profile (P5-P5, Fig. 19) by using simple graphical method. Because $\mathrm{FX}=0$ at $\mathrm{X}=$ $\mathrm{XM}$ or Xm, this (P5-P5) profile enables precise determination of the values of $\mathrm{XM}$ and $\mathrm{Xm}$ after the epicentral position $\mathrm{FX}=0$, has been located using the above method (Powell 1967).

3. The values of FX0 and FXU where $\mathrm{U}=1 / 2(-\mathrm{Xm} \times \mathrm{XM})$, are now read and 


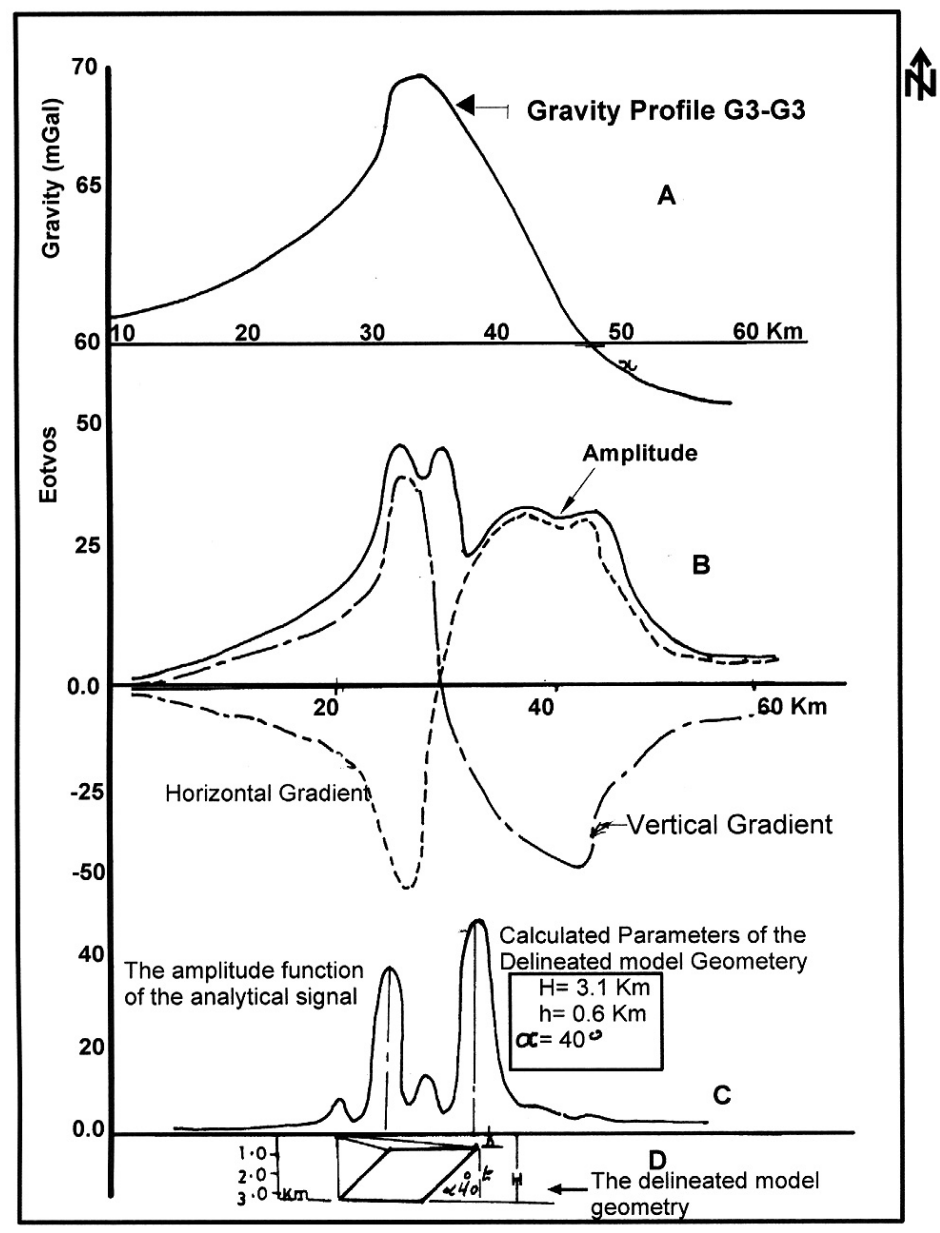

Fig. 18. Quantitative interpretation along gravity profile G3-G3. A: gravity profile; B: horizontal gradient and vertical gradient with the analytical signal; C: the amplitude function oft he analytical signal; D: the delineated model geometry

used, together with the known values of XM and Xm for the estimation of $\theta F$ from the equation

$$
\theta F=\tan U /(x m+X M) .
$$

4. the depth to the basement complex is then estimated from known values $\mathrm{Xm}$, $\mathrm{XM}$ and $\tan \theta F$ according to the equation

$$
h=-\frac{1}{2}(X m+X M) \tan \theta F .
$$

Figure 19 shows an interpreted example for depth estimation using the Poorna method. For the interpretation of magnetic anomalies, the technique was applied 
Table I. Buried bodies parameters estimated from the magnetic and gravity data using Helbert transform technique

\begin{tabular}{|c|c|c|c|c|c|c|}
\hline Profile number & Potential data & $\mathrm{H}$ & $\mathrm{h}$ & W & $\dot{\alpha}$ & $\varrho$ \\
\hline $\mathrm{A} 1-\mathrm{A} 1$ & magnetic & 3.10 & 0.65 & 3.30 & $41^{\circ}$ & - \\
\hline $\mathrm{A} 2-\mathrm{A} 2$ & magnetic & 3.10 & 0.80 & 3.80 & $35^{\circ}$ & - \\
\hline $\mathrm{A} 3-\mathrm{A} 3$ & magnetic & 2.70 & 0.55 & 3.20 & $32^{\circ}$ & - \\
\hline $\mathrm{A} 4-\mathrm{A} 4$ & magnetic & 2.40 & 0.66 & 2.70 & $30^{\circ}$ & - \\
\hline A5-A5 & magnetic & 3.30 & 0.60 & 2.40 & $27^{\circ}$ & - \\
\hline $\mathrm{A} 6-\mathrm{A} 6$ & magnetic & 2.60 & 0.54 & 2.20 & $33^{\circ}$ & - \\
\hline $\mathrm{A} 7-\mathrm{A} 7$ & magnetic & 2.10 & 0.52 & 2.00 & $39^{\circ}$ & - \\
\hline A $8-\mathrm{A} 8$ & magnetic & 2.00 & 0.48 & 1.80 & $42^{\circ}$ & - \\
\hline G!-G1 & gravity & 3.20 & 0.82 & 4.00 & $46^{\circ}$ & 0.27 \\
\hline G2-G2 & gravity & 2.90 & 0.70 & 3.52 & $51^{\circ}$ & 0.23 \\
\hline G3-G3 & gravity & 3.10 & 0.60 & 2.60 & $40^{\circ}$ & 0.29 \\
\hline G4-G4 & gravity & 2.63 & 0.54 & 3.00 & $50^{\circ}$ & 0.24 \\
\hline G5-G5 & gravity & 2.82 & 0.51 & 2.73 & $48^{\circ}$ & 0.22 \\
\hline \multicolumn{7}{|c|}{$\begin{array}{l}\text { is the depth to the lower surface in kilometers } \\
\text { is the depth to the upper surface in kilometers } \\
\text { is the width of the dyke } \\
\text { is the dip angle of the dyke plane } \\
\text { is the density contrast between the dyke and its surroundings. }\end{array}$} \\
\hline
\end{tabular}

to a set of profiles taken from the RTP aeromagnetic map (Fig. 15). This method has been applied to a set of profiles (P1-P1, P2-P2, P3-P3, P4-P4 and P5-P5). The location of these profiles is illustrated in Fig. 15. The obtained results are listed in Table II.

\section{Depth estimation based on the spectral analysis technique}

Several authors such as Troshkov and Shalavc (1961), Solovyev (1962), Bhattacharrya (1966), Spector and Grant (1970), Garcia and Ness (1994) and Mauirizio et al. (1998) explained the spectral analysis technique.

Treitel et al. (1971) calculated the energy spectrum of the aeromagnetic data 


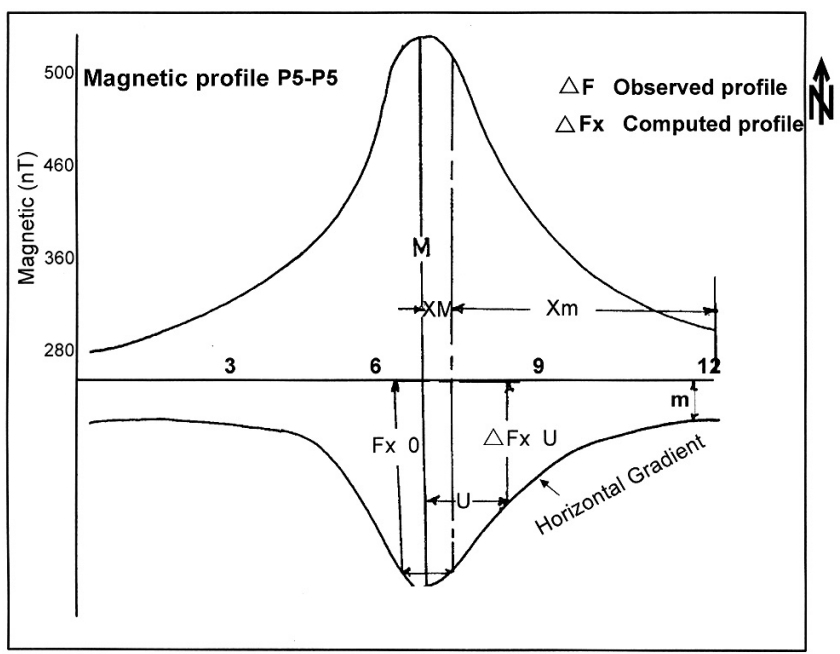

Fig. 19. Quantitative interpretation along magnetic profile P5-P5 using Proona method (1985)

Table II. Results of depth estimation using Poorna method (1985)

\begin{tabular}{cc}
\hline Profile number & Depth of the basement complex (km) \\
\hline P1-P1 & 2.6 \\
\hline P2-P2 & 3.0 \\
\hline P3-P3 & 2.2 \\
\hline P4-P4 & 2.3 \\
\hline P5-P5 & 2.8 \\
\hline
\end{tabular}

taken through one-dimensional depth from the geophysical diagrams of the normalized log-amplitude spectrum, and by considering the depth " $\mathrm{D}$ " to be:

$$
D=2 d / \Delta \zeta
$$

where

$\Delta \zeta: \quad$ is the uniform sampling increment.

$D: \quad$ is the actual depth of the anomaly source.

Then

$$
S j=\exp \{-(\pi j / M) D\}
$$

where $j=0,1,2, \ldots, M$. 
Table III. Results of depth estimation using the spectral analysis technique

\begin{tabular}{lccc}
\hline Profile number & Potential data & $\begin{array}{c}\text { Depth of the } \\
\text { basement complex } \\
(\mathrm{km})\end{array}$ & $\begin{array}{c}\text { Depth of the } \\
\text { basement intrusion } \\
(\mathrm{km})\end{array}$ \\
\hline S1-S1 & magnetic & 3.20 & 0.45 \\
S2-S2 & magnetic & 2.93 & 0.55 \\
S3-S3 & magnetic & 3.10 & 0.51 \\
S4-S4 & magnetic & 3.15 & 0.47 \\
S5-S5 & magnetic & 3.00 & 0.49 \\
S6-S6 & magnetic & 2.85 & 0.55 \\
S7-S7 & magnetic & 3.30 & 0.60 \\
S8-S8 & magnetic & 3.00 & 0.52 \\
L1-L1 & gravity & 2.90 & 0.60 \\
L1-L1 & gravity & 3.10 & 0.54 \\
L3-L3 & gravity & 2.80 & 0.55 \\
L4-L4 & gravity & 2.90 & 0.48 \\
L5-L5 & gravity & 3.30 & 0.58 \\
L6-L6 & gravity & 3.10 & 0.52 \\
\hline
\end{tabular}

So that

$$
\ln S j=[-(\pi j / M) D]
$$

where

$S j: \quad$ is the theoretical normalized power spectrum in terms of $(j)$

$M:$ is the maximum log value for the auto correlation of the series.

$T i: \quad$ is $=1,2,3, \ldots, N$

$N: \quad$ is the gate length.

The determination of $(D)$ can be achieved by measuring the slope of the log normalized power spectrum $(S j)$ at the lower and total wave number and knowing $(\Delta \zeta)$, the depth $(d)$ can be obtained as follows:

$$
d=1 / 2 D . \Delta \zeta .
$$

For the interpretation of magnetic anomalies, the technique was applied to a set of profiles taken from the RTP aeromagnetic map and Bouguer gravity map (Fig. 20 ). The log power spectra obtained from the profiles (S1-S1 and L1-L1) are shown in Fig. 20. Table III summarizes the results from this analysis.

\section{Summary and discussion}

Magnetic and gravity data in the North and Central Sinai area were used integratively to delineate the structural features and the tectonic inferences of the studied area. According to the obtained results, the following were concluded about the tectonics of the area:

1. The general magnetic and gravity trends pattern is NE-SW and NW-SE. These trends indicate that there are at least two essential structural morphological elements mostly reflecting the presence of dislocation in the basement surface. 

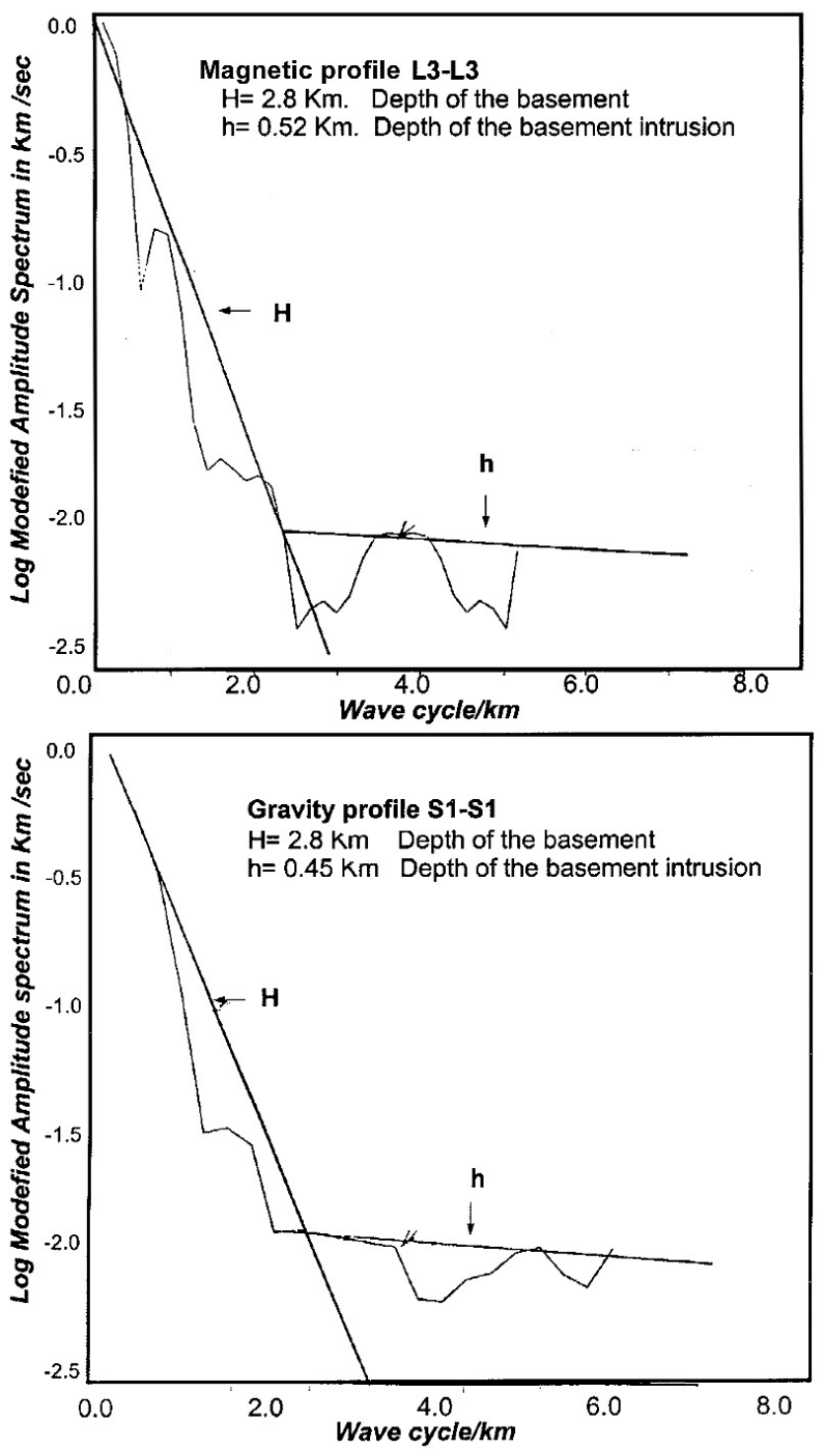

Fig. 20. Log modified amplitude spectrum along profiles L3-L3 and S1-S1

2. The central part of the area is structurally controlled by tectonics having major magnetic and gravity axis NW-SE and NE-SW direction, which separates this part from the main depression and platform area.

3. Local tectonic boundaries were recorded in the central and western parts of the area. These boundaries are probably due to lithological changes within the thick sedimentary cover as well as to tectonic deformation and basaltic intrusion. 
4. The trend analysis technique was applied to RTP aeromagnetic map, gravity map, and regional filtered maps, in order to detect the continuation of the tectonics under the sedimentary section to the basement complex. The results of such studies proved the possible relationships of magnetic and gravity data. The predominant tectonic trends are NE-SW, NW-SE and E-W. These trends correspond to the high magnetic and gravity anomalies in the area.

5. From the analysis of the $2 \mathrm{D}$ model along a set of magnetic and gravity profiles across the different structural units, it was concluded that, the models exhibit a number of peaks which indicate the locations of shallow magnetic and gravity structures underlying the area. The depth of the top of the basement at those peaks is in the range of $1.2 \mathrm{~km}-2.4 \mathrm{~km}$, and the depth to the basement at the deeper parts is from $3.6 \mathrm{~km}-4.3 \mathrm{~km}$.

6. Hilbert transform technique is used for the calculation of buried body parameters using the gravity and magnetic data. The results obtained upon calculating the body parameters are, $27^{\circ}$ to $51^{\circ}$ for the dip angle, $0.51 \mathrm{~km}$ to $0.82 \mathrm{~km}$, for the depth to the upper surface and $2.0 \mathrm{~km}$ to $3.10 \mathrm{~km}$ for the depth to the lower surface. In addition, the density contrast was estimated to be about $0.25 \mathrm{gm} / \mathrm{cm}^{3}$.

7. The depth values which are computed by different methods and techniques for a single anomaly did not show much difference. The average depth to the basement surface ranges between $2.2 \mathrm{~km}$ and $3.2 \mathrm{~km}$, while the average depth to basement intrusions ranges between $0.51 \mathrm{~km}$ and $0.80 \mathrm{~km}$.

Magnetic and gravity interpretations play an important role in resolving the subsurface tectonic implications. Also, it is clear that the magnetic and gravity methods proved their accuracy as a geophysical tool in explaining the near surface tectonic that is controlling the local structures.

\section{References}

Baranov V 1975: Geoexploration Monograph, Series L, No. 6, Gerbruder Borntraeger, Berlin, Stuttgart

Bhattacharrya B K 1966: Geophysics, 31, 97-121.

Domazalaski W 1966: Geophys. Prospect., 14, 273-291.

Folkman Y, Assel 1980: Sinai gravity and magnetic map. The Institute for Petroleum Research and Geophysics, Israel

Garcia J G, Ness G E 1994: Geophysics, 59, 391-400.

GM-SYS 1995: Gravity and magnetic modeling version 3.6. Northwest Geophysical Association, Inc. (NGA), Corvallis, Oregon, USA 97339

Halsey J H, Gardner W C 1975: Tectonic of Egypt using Earth satellite data. Lecture given to Egyptian Geologists in Cairo

Harland W B 1971: Geol. Mag., 108, 27-42.

Lowell J D 1972: Bull. Geol. Soc. Am., 83, 3091-3101.

Maurizio F, Tatina Q, Angelo S 1998: Geophysics, 62(4), 1143-1150.

Poorna C 1985: Geoph., 50, 1179-1182. 
Powell D V 1967: Geophys. Prosp., 15, 208-220.

Said R 1990: The Geology of Egypt. Balkemor Publishers, Rotterdam

Smith A G 1971: Bull. Geol. Soc. Am., 82, 2039-2070.

Solovyev O A 1962: Sibirskoye Otddelniye Geologia, Geofizika, 2, 122-125.

Spector A, Grant F S 1970: Geophysics, 35, 293-302.

Stanley S M 1977: Geophysics, 42, 1236-1240.

Steinitz G, Bartov Y, Hunziker J C 1978: Geol. Mag., 115, 329-340.

Sylvester A G, Smith R R 1976: Bull. Am. Assoc. Petrol. Geol., 60, 1625-1640.

Tchalenko J 1970: Bull. Geol. Soc. Am., 81, 1625-1640.

Treitel S, Clement W G, Kaub R K 1971: J. R. Astr. Soc., 24, 415-428.

Troshkov G A, Shalave S A 1961: Prein. Geofiz., 30, 162-178.

Wilcox R E, Harding T P, Wilcox R E, Hardingsd R, Seely R 1973: Bull. Am. Assoc. Petrol. Geol., 57, 74-96. 